\title{
THE IMPACT OF GOVERNMENT AGRICULTURAL EXPENDITURE ON POVERTY IN ZIMBABWE
}

\author{
Alexander Mapfumo, Abbyssinia Mushunje, Researchers ${ }^{1}$ \\ Clainos Chidoko, Researcher ${ }^{2}$ \\ ${ }^{1}$ University of Fort Hare, Republic of South Africa \\ ${ }^{2}$ Great Zimbabwe University, Masvingo, Zimbabwe \\ E-mail: cchidoko@gmail.com
}

Received June 27, 2012

\begin{abstract}
Global experience with pro-poor growth and empirical work spanning India, Benin and Malawi demonstrates the importance of agricultural expenditure for poverty reduction in poor rural areas, while also pointing to the need for complementary non farm sector growth. This paper proposes a simple methodology to estimate the agricultural spending that will be required to achieve the Millennium Development Goal of halving poverty by 2015 (MDGs) in Zimbabwe. This method uses growth poverty and growth expenditure elasticities to estimate the financial resources required to meet the MDGs. The paper attempts to address a key knowledge gap by improving estimation of first MDG agricultural expenditure at country level.
\end{abstract}

\section{KEY WORDS}

Poverty; Millennium; Development Goals; Agricultural spending; Expenditure.

World Bank report (2004) reiterated that poverty has fallen rapidly over the past 40 years, but at different rates around the world. Asia has achieved the highest poverty reduction, particularly China, India and South East Asia (World Bank, 2004). However, little if any progress was made in sub-Saharan Africa, where the number of people living on less than one dollar a day has doubled since 1980 (World Bank, 2004).

After independence in 1980, Zimbabwe had impressive progress in reducing poverty as reflected by the reduction of extreme poverty rates from 32 percent in 1980 to around 26 per cent in 1991 due to increase in agricultural support services such as research, extension, credit and marketing on the part of the smallholder farmers (Bird \& Prowse, 2008). However this was reversed to the extent that by 2003 , some 72 per cent of the population lived below the national poverty line and the living conditions of the population became some of the worst in Africa (Bird $\&$ Prowse, 2008).

The potential contribution of agriculture to poverty reduction has been a greatly debated subject among development economists. Much of the early work on this issue coincided with the debate on the role of agriculture in promoting economic development in less developed countries in the aftermath of extended periods of colonial rule (Lewis, 1954, Fei and Ranis, 1961; Jorgenson, 1961; Johnston and Mellor, 1961; Schultz, 1964).

After independence, the percentage of the population classed as poor has been increasing. Data from the Central Statistical Office (2003) suggest that by 2000 , poverty in Zimbabwe was already on the rise. From a low of around 26 per cent in 1991 the proportion of households living below the food poverty (extreme poverty) line rose to 35 per cent by 1995 , before a dramatic rise to 63 per cent by 2003. The Human Poverty Index by UNDP, (2008) was at 17 per cent in 1990, an impressively low figure by African standards. However, by 2006 it was estimated to have more than doubled to 40.9 per cent. Similarly the country has been sliding down the UN's Human Development Index ranking from a respectable 52 in 1990, the country was ranked 108 in 1992, 129 in 1997 and by 2005 it was ranked at 155 of the 177 countries.

Two major surveys (ICES and PASS) conducted in 1995 showed the proportion of the population classed as poor to be in excess of $60 \%$. However, the absolute figures for those in poverty are crucially dependent on the poverty line chosen. Using the poverty line adopted by 
the International Development Targets, that is the number of people with incomes under US\$1 per day, (DFID, 1999) estimate that there were around five million poor people in Zimbabwe which was around $40 \%$ of the total population. Given this scenario, it is therefore imperative to determine the expenditure options between agricultural and non agricultural expenditure necessary to meet the first MDG goal, which is to half poverty by half by 2015 .

The land in Zimbabwe is divided into five natural regions on the basis of soil type and climatic factors (refer to Figure 1). The bulk of Mashonaland (West, East and Central), Midlands and Manicaland Provinces are under regions I, II and III, while Matabeleland (North and South) and Masvingo Provinces are under natural regions IV and V.

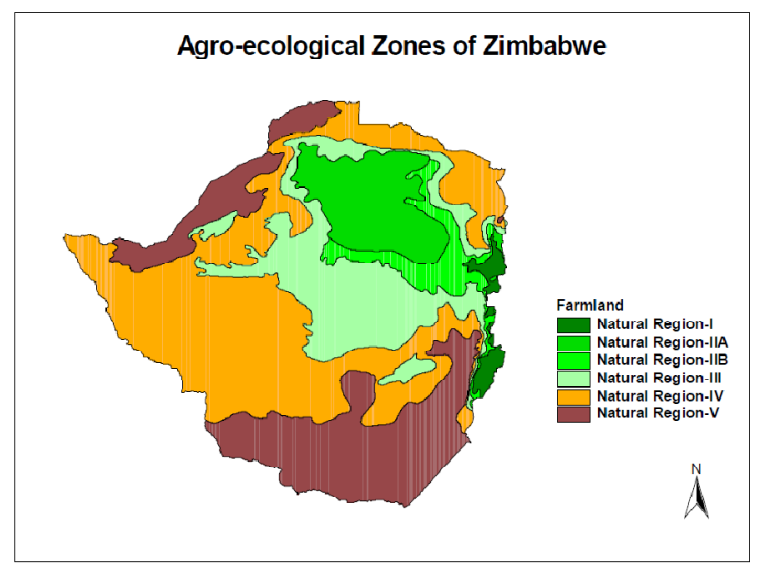

Figure 1 - Agro-ecological zones in Zimbabwe (F.A.O., 1999)

About 38 per cent of the country was deemed to have natural farming potential (Bell \& Roberts 1991). Region I was seen as suitable for specialized and diversified farming, especially activities related to forestry, fruit and intensive livestock production. Region II was deemed suitable for diversified farming that includes production of flue-cured tobacco, maize, cotton, sugar, beans, coffee, sorghum, groundnuts, seed maize, barley and related horticultural crops. It was also seen to have potential for irrigated winter wheat, poultry, beef and dairy production. Most parts of Natural Region III with suitable terrain were seen as being marginally suitable for semi-intensive farming especially the production of grains and livestock. The largest number of rural residents is found in Natural Region IV (NRIV) (just over 2.5 million in 2002), and it is also clear that the largest number of rural poor is found in this natural region (Central Statistical Office, 2003).
Moreover, the Central Statistical Office (2003) also found that the highest incidence of rural poverty to be in Matabeleland North (88.2 per cent of households), followed by Mashonaland Central (85.2 per cent), Matabeleland South (86.6 per cent) and Masvingo (84.0 per cent). As Table 1 suggests, poverty follows types of farming system and consequently natural or regional agro-ecological conditions.

Table 1 - Poverty by Natural Region*

\begin{tabular}{|c|c|c|}
\hline Natural Region & Prevalence $(\%)$ of \\
\hline I & Poverty & Extreme Poverty \\
\hline II & 62.4 & 36.2 \\
\hline III & 71.6 & 41.2 \\
\hline IV & 77.3 & 51.4 \\
\hline V & 81.6 & 57.2 \\
\hline & 79.5 & 55.7 \\
\hline
\end{tabular}

* Source: Central Statistical Office, (2003)

Public investment and poverty. Public investment affects rural poverty through many channels, as depicted in Figure 2. For example, public investment in agricultural research, rural education, and infrastructure increases agricultural productivity, which directly increases farmers' incomes and in turn reduces rural poverty (Fan $e t$ $a l, 2008)$. Moreover, indirect impacts come from higher agricultural wages and improved nonfarm employment opportunities induced by growth in agricultural productivity. Increased agricultural output from rural investment often leads to lower food prices, again helping the poor indirectly because they are often net buyers of food grains.

Furthermore, Public investments in rural education, health, and infrastructure not only have indirect effects on wages, nonfarm employment, and migration through increased productivity, but also directly promote rural wage increases, nonfarm employment, and migration, thereby reducing rural poverty (Fan et al, 2009). For example, improved infrastructure access will help farmers set up small rural nonfarm businesses such as food-processing and marketing enterprises; electronics repair shops, transportation and trade, and restaurants.

Fan et al, (2008) explained that understanding these different effects provides useful policy insights for improving the effectiveness of national poverty reduction strategies. In particular, an understanding of these effects shows how public investment can be used to strengthen weak links between poverty reduction channels and thus to target public resources more efficiently. More efficient targeting has become increasingly crucial as many developing countries have committed to 
achieving poverty reduction goals using the Millennium Development Goal (MDG) framework with limited public resources (Fan et al, 2008).

Public spending plays a critical role in antipoverty interventions in terms of influencing the resource allocation by providing physical and social infrastructure which would help to accelerate growth and/or to direct the benefits of growth to the poor (Datt and Ravallion, 2002).

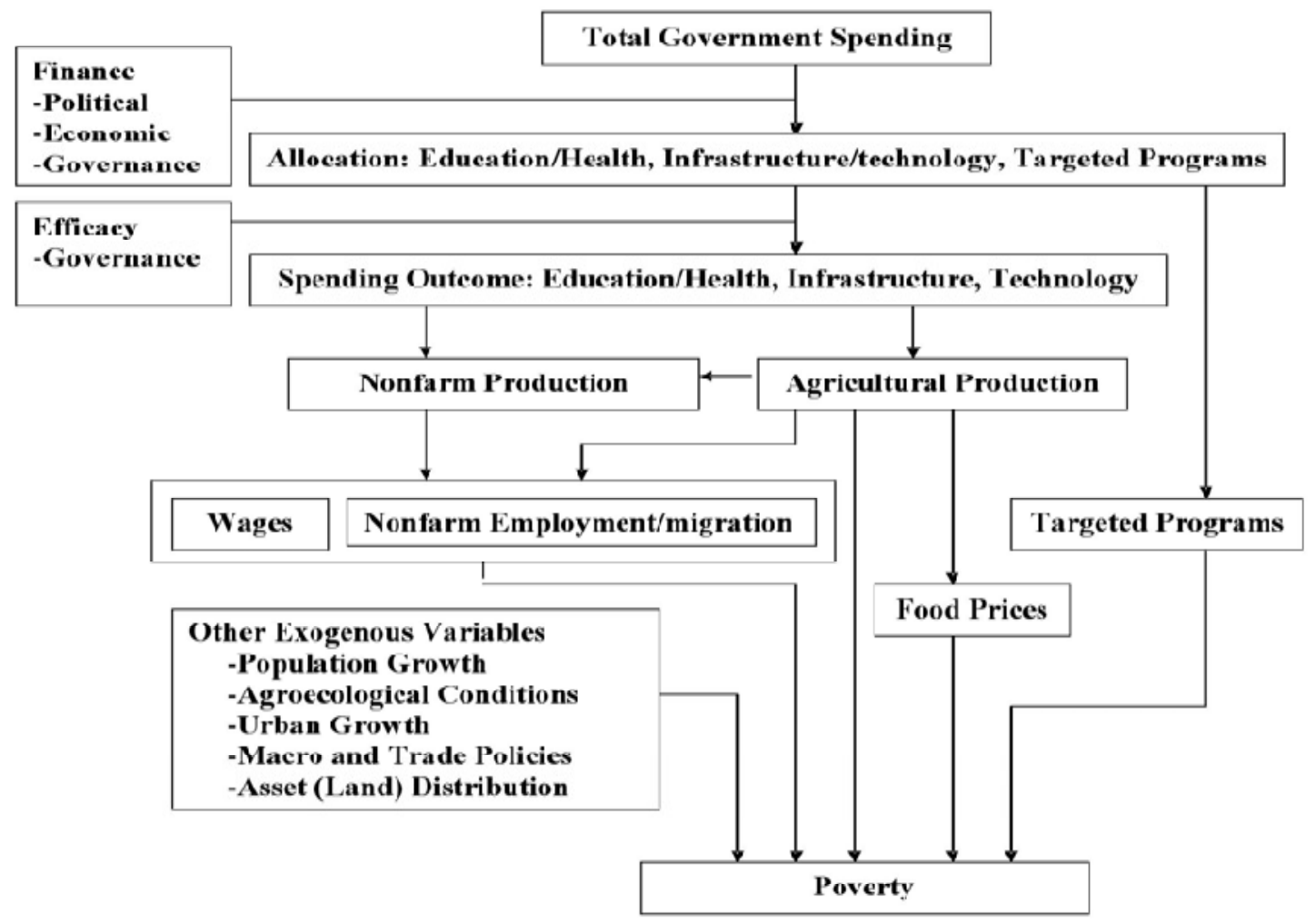

Figure 2 - Government spending and poverty (Datt and Ravallion, 2002)

Several studies have estimated the effect of public expenditure, including public investment expenditure, on poverty. Using cross-country data, Gomanee et al, (2003) and Mosley et al, (2004) have estimated the effects of government expenditure in different sectors on the US $\$ 1$ a day poverty headcount, holding the level of GDP per capita constant. Gomanee et al, (2003) and Mosley et al, (2004) found that higher government expenditure on education, agriculture, and housing and amenities (water, sanitation and social security) all have a negative and statistically significant impact on poverty, presumably by shifting the distribution of income in a pro poor direction, since the level of aggregate income is held constant in their regressions.

Other studies have used cross-state data, particularly in India where state-level data are highquality and stretch far back in time. Fan et al, (1999), for instance, estimate the effect of public expenditure on levels of rural poverty across Indian states, distinguishing between expenditure on rural education, targeted rural development, public health, irrigation, power generation, agricultural R\&D, and rural roads. Fan et al, (1999) found that agricultural $\mathrm{R} \& \mathrm{D}$, rural roads, rural education and targeted rural development expenditure all have negative and statistically significant effects on rural poverty. Of these, spending on agricultural $R \& D$ and rural roads has by far the largest impacts on both growth and poverty reduction. Fan et al, (2002) conducted a similar analysis of the effects of public expenditure on rural poverty across Chinese provinces, distinguishing between expenditure on rural education, targeted poverty alleviation, telecommunications, irrigation, power generation, agricultural $R \& D$, and rural roads. They find that spending on rural education has the largest impact on poverty, followed by spending on agricultural $R \& D$ and then by spending on rural roads.

Similarly, Datt and Ravallion (2002) estimated the determinants of differences in the rate of reduction of the poverty headcount across Indian states over the period 1960-1994. Datt and Ravallion (2002) concluded that state government de- 
velopment spending has a large and statistically significant effect on poverty reduction, even when controlling for changes in agricultural and non agricultural productivity and a time trend.

\section{MATERIALS AND METHODS}

Data sources and type. The study will be carried out using secondary data. Unless otherwise specified all the data will be drawn from the Central Statistics Offices (CSO), Ministry of Finance (MOF) and Ministry of Agriculture (MOA) of Zimbabwe. In this study annual time series data will be used covering the period from 1980 to 2009.

Estimation of spending towards agriculture for poverty reduction. To estimate required growth and spending on agriculture and non agriculture, a simple simulation model used by Fan $e t$ $a l$, (2008) was adopted. For the purposes of estimating required agricultural growth rates, the model starts by decomposing a typical growth elasticity of poverty into the effects of agricultural and non agriculture growth. Unable to obtain any reliable data or estimates in Zimbabwe, the multiplier effect or linkage between agriculture and non-agricultural expenditure have been ignored in this study. The decomposition of growth elasticity of poverty into the effects of agricultural and non agriculture growth can be represented for the country as follows:

$$
\frac{d P}{P}=\left(\frac{d Y}{P} \frac{Y_{a g}}{d Y_{a g}}\right) \frac{d Y_{a g}}{Y_{a g}} s_{a g}+\left(\frac{d P}{P} \frac{Y_{n g}}{d Y_{n g}}\right) \frac{d Y_{n g}}{Y_{n g}} s_{n g},
$$

where $\mathrm{P}=$ poverty rate; $\mathrm{Y}_{\mathrm{ag}}=$ agricultural GDP; $\mathrm{Y}_{\mathrm{ng}}=$ non-agricultural GDP; $\mathrm{S}_{\mathrm{ag}}=$ share of agriculture in GDP; $S_{n g}=$ share of non-agriculture in GDP.

Equation (1) can be rewritten as:

$$
\dot{P}=\left\{\varepsilon_{a g} * g_{a g}\right\} * S_{a g}+\left\{\varepsilon_{n g} * g_{n g}\right\} * S_{n g},
$$

where $\dot{P}=$ change in poverty for each year; $\mathcal{E}_{a g}=$ elasticity of poverty reduction with respect to (w.r.t.) agricultural GDP growth; $\varepsilon_{n g}=$ elasticity of poverty reduction w.r.t. non-agricultural GDP growth; $g_{a g}=$ agricultural GDP growth rate; $g_{n g}=$ non-agricultural GDP growth rate; $S_{n g}=$ share of non-agriculture in GDP.
The contributions of agricultural and nonagricultural growth on poverty reduction, weighted by their respective shares in total GDP are represented by equation 2 . The first and second terms measure the direct and independent effects of agricultural and non-agricultural growth on poverty reduction. The third term measures an indirect effect whereby additional reductions in poverty, which result from nonagricultural growth, are solely generated by the multiplier effect or linkage with agricultural growth. Partitioning the expected reduction in poverty among each of the terms in equation (2) and solving for the required agricultural growth rate (as the unknown) yields the following equation:

$$
g_{a g}=\left\{\dot{P}-\dot{P}_{n g}\right\} /\left\{\varepsilon_{a g} * S_{a g}\right\},
$$

where $\dot{P}_{n g}=$ the rate of poverty reduction emanating from a given non-agricultural growth rate, which is calculated from the second term in equation (2), i.e.:

$$
\dot{P}_{n g}=\varepsilon_{n g} * g_{n g} * S_{n g} .
$$

Equation (3) represents the agricultural growth rate that is required to reduce poverty annually from its own direct effect. The level of public expenditure needed for agriculture to grow is calculated in equation (3) and once the required agricultural growth rates are known, the corresponding annual changes in expenditure needed to achieve these growth rates can be calculated as:

$$
\dot{E}_{a g}=g_{a g} / \delta_{a g},(4)
$$

$\dot{E}_{a g}=$ the annual growth rate in agricultural expenditures, $\delta_{a g}=$ elasticity of agricultural growth w.r.t. agricultural expenditure growth which is calculated as:

$$
\frac{d Y_{a g}}{d E_{a g}} * \frac{E_{a g}}{Y_{a g}} .
$$

The annual agricultural expenditures required between 2011 and 2015 can be easily calculated from the data on actual agricultural expenditures in 2010 for Zimbabwe from equation (4). The regression analyses will be performed using Econometric-views 7 (E-views 7) statistical package. 


\section{RESULTS}

The trend of poverty is illustrated on Figure 3 using data collected from CSO. It shows that poverty generally increased from 1980 to 2003 (though it has been fluctuating) which means that the standard of living or Zimbabweans has been falling over the period. Poverty has been very high when the agricultural sector did not perform well due to droughts of 1992 and 2002.
Estimation of spending towards agriculture for poverty reduction. Using growth elasticities and projected growth rates, we can simulate whether Zimbabwe will be able to halve the number of poor by 2015. Firstly, elasticities of poverty reduction with respect to agricultural GDP growth and poverty reduction with respect to non agricultural GDP growth from equation 2 on 4.2 can be calculated using a simple log linear model with econometric views 7 and the results are shown on Table 2 below.

Table 2 - Review of elasticities of poverty reduction

\begin{tabular}{|c|c|c|c|c|}
\hline Variable & Coefficient & Std. Error & t-Statistic & Prob. \\
\hline $\mathrm{C}$ & 4.337878 & 0.723559 & 5.995200 & 0.0001 \\
\hline LOGAG & 0.068200 & 0.030975 & 2.749648 & 0.0679 \\
\hline LOGNAG & -0.094590 & 0.028706 & -2.611268 & 0.0331 \\
\hline
\end{tabular}

Table 3 - Review of elasticity of agricultural growth with respect to agricultural expenditures

\begin{tabular}{|c|c|c|c|c|}
\hline Variable & Coefficient & Std. Error & t-Statistic & Prob. \\
\hline $\mathrm{C}$ & 10.26840 & 1.533442 & 6.696311 & 0.0000 \\
\hline LOGEAG & 0.572402 & 0.189356 & 3.022891 & 0.0063 \\
\hline
\end{tabular}

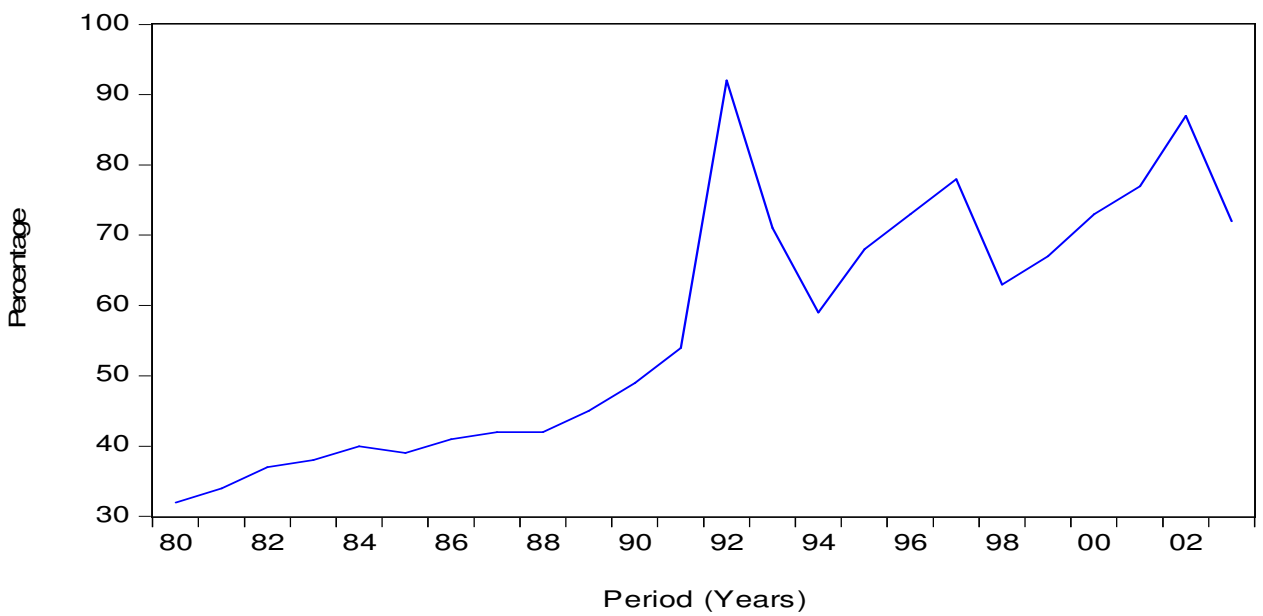

Figure 3 - Trend of poverty in Zimbabwe, 1980-2003

From Table 2, it can be deduced that the elasticity of poverty reduction with respect to with respect to agricultural GDP growth, $\varepsilon_{a g}=$ 0.068 and elasticity of poverty reduction with respect to non agricultural GDP growth, $\varepsilon_{n g}=-$ 0.0945. Substituting the results into equation 3 yields that the required agricultural growth rate, $g_{a g}=0.308$. Furthermore, = elasticity of agricultural growth with respect to agricultural expenditure growth, $\delta_{a g}$ can be calculated using a simple log linear model with econometric views 7 and the results are shown in Table 3. Thus, $\delta_{a g}=0.572$, means that for every one percent increase in real agricultural growth, real agricultural GDP increases by $0.57 \%$ on average. Substituting $g_{a g}$ and $\delta_{a g}$ into equation 4 on 4.2 will result in the annual growth rate in agricultural expenditures, $\dot{E}_{a g}$ to be equal to 0.538 . This means that the annual growth rate expected in agricultural expenditures required between 2011 and 2015 to half poverty in Zimbabwe is 54 percent. Therefore the annual agricultural expenditures required in 2011 give US \$ (1.54x97.2 $\left.\mathrm{M}^{* *}\right)$, which translates to US $\$ 149.69 \mathrm{M}$. This also means that the agricultural expenditures required in 2012 will be given by US $\$(1.54 \times 149.69 \mathrm{M})$ which will amount to US $\$ 230.69 \mathrm{M}$. 
** Using data on budgeted agricultural expenditures in 2010 for Zimbabwe (MOF, 2009). As a result the agricultural expenditures which will be required for 2013 give US $\$(1.54 \times 230.69 M)$, translating to US \$355.26M. For 2014, the annual agricultural expenditures required give US \$ (1.54* 355.26), whose total will be US \$547.10M. Finally the annual agricultural expenditures required in 2015 will be given by US \$ (1.54x547.10M), which translates to US $\$ 842.53$. Therefore the agricultural expenditures required between 2011 and 2015 gives US \$ (149.69 M+230.69M + 355.26M + $547.10+842.53)$, which translates to US $\$ 2.125$ billion.

These results are slightly higher than the results of annual growth rate required in agricultural expenditures of 50 percent in spending by Fan S et al, (2008). This indicates a worsening situation and therefore renders it very difficult to meet the first MDG to half poverty by 2015. Using results from Fan S et al, (2008), other countries such as Lesotho, Niger, Kenya, Madagascar, Guinea Bissau and Burundi will require at least 10 percent growth in agriculture, while Ghana has an achievable level of 9.5 percent. Moreover, given that Madagascar had a too far more difficult level of 33 percent in the study by Fan S et al, (2008), it will prove to be an almost impossible task for Zimbabwe to to meet the first MDG to half poverty by 2015 .

\section{CONCLUSION}

Poverty reduction is a priority for all African countries. Pro poor growth requires attention on productive sectors such as agriculture and infrastructure. Growth must be focused on sectors where the poor depend on for their livelihood and use the factors of production they possess such as agriculture. It is imperative, as we move forward in our efforts to achieve the first MDG, that support should be prioritized to the set of sectors needed for rapid and sustained poverty reduction in Zimbabwe, such as agriculture. The results of the study have policy implications for improved decisions regarding investment policies for agriculture, so that they contribute more effectively to development and poverty reduction in Zimbabwe. In order to achieve the MDG1, the analysis in this thesis indicates that Zimbabwe will need 54 percent annual growth rate in spending towards agriculture. The estimated spending towards agriculture for poverty reduction in tandem with first MDG was found to be very high which make it almost impossible for the Zimbabwe government to meet the first MDG indicating that the country needs to accelerate their economic growth, particularly in the agricultural sector.

Several studies note the central role of agriculture in reducing poverty, especially in the African context. However, while it is vital to estimate the public resources needed to reach particular agricultural targets, it is equally important to prioritize investments. Limited evidence shows that investments in agricultural research and extension, rural infrastructure and rural education have the greatest impact on agricultural growth and poverty reduction (Fan, Zhang and Rao, 2004).

Although the estimated spending towards agriculture for poverty reduction in tandem with first MDG was found to be very high, which makes it almost impossible for the Zimbabwe government to meet the first MDG; the government nevertheless needs to continue channelling resources to the sector within its means to significantly reduce poverty in the country. The efficient use and targeting of these large public expenditures will require a complementary strengthening and reformation of governance and institutions. Therefore, it remains essential that policy makers need to focus on ensuring that the increase in the size of expenditure should be complemented by increase in output from the agricultural sector.

\section{REFERENCES}

Bell M \&Roberts N (1991). 'The Political Ecology of Dambo Soil and Water Resources in Zimbabwe', Transactions of the Institute of Geographers, New Series, vol. 16, no. 3, pp. $301-318$.

Bird K \& Prowse M (2008). Vulnerability, poverty and coping in Zimbabwe. United

Nations University. UNU-WIDER Research Paper 2008/41.

Datt G \& Ravallion M (2002). 'Is India's Economic Growth Leaving the Poor Behind?', Journal of Economic Perspectives, Vol.16, no. 3, pp. 89-108.

Fan S, Zhang X, \& Rao N (2004). Public expenditure, growth, and poverty reduction in rural Uganda. Development Strategy 
and Governance Division Discussion.

Fan S, Zhang X \& Zhang L (2002). "Growth, inequality and poverty in rural China", Research papers 125, International Food Policy Research Institute (IFPRI).

Fan S, Hazell P \& Thorat S (1999) Linkages Between Government Spending, Growth and Poverty in Rural India. Research Report 110. Washington, DC: IFPRI.

Fan S \& Johnson M \& Saurkar A \& Makombe $\mathrm{T}$ (2008). Investing in African agriculture to halve poverty by 2015 . IFPRI discussion papers 751, International Food Policy Research Institute (IFPRI).

Fei J \& Ranis G (1961). "A theory of economic development." American Economic Review, Vol.51, no. 4, pp. 533-565.
Gomanee K, Morrissey O, Mosley P \& Verschoor A (2003). Aid, Pro-poor Government Spending and Welfare. CREDIT Research Paper 3. Nottingham: University of Nottingham, CREDIT.

Jorgenson D (1961). "The development of a dual economy." Economic Journal, Vol.282, pp. 209-334.

Lewis W A (1954). Economic Development with Unlimited Supplies of Labour. The Manchester School. Vol. 22, pages 3-42.

Mosley P, Hudson J \& Verschoor A (2004). "Aid, Poverty Reduction and the "New Conditionality", Economic Journal 114, June: F217-F243.

UNDP (2008), 'Comprehensive Economic Recovery in Zimbabwe'. A discussion document. UNDP Zimbabwe. 